\title{
Extended Letrozole Regimen for Treatment of Clomiphene Resistant Polycystic Ovary Syndrome Patients
}

\author{
Ahmed W. Anwar, Ehab E. Barakat, Ahmed M. Bayomey, Manal H. Ahmed
}

\begin{abstract}
Department of Obstetrics and Gynecology, Faculty of Medicine Benha University, Egypt.
\end{abstract}

Correspondence to: Manal H. Ahmed, Department of Obstetrics and Gynecology, Faculty of Medicine Benha University, Egypt.

Email:

manal-hassen@hotmail.com

Received: 22 October 2019

Accepted: 17 October 2021

\begin{abstract}
:
Background: Polycystic Ovary Syndrome (PCOS) is one of the most common causes of an-ovulatory, $4-7 \%$ of women, The aim of the study was to compare the extended letrozole regimen with the classical one in treatment of CC resistant PCO patients, Subjects and Methods: 60 infertile, PCO and CC resistant women were divided randomly into 2 groups, group I, (short letrozole therapy) received $2.5 \mathrm{mg}$ twice daily from 2 nd day of cycle for 5 days and repeated for 3 cycles (classical regimen) and group II, (long letrozole therapy) treated by $2.5 \mathrm{mg}$ once daily from $2 \mathrm{nd}$ day of cycle for 10 days and repeated for 3 cycles (extended regimen). Follicular growth and endometrial thickness monitoring, in all patients was performed regulary by trans-vaginal ultrasound. On day 10 of the cycles. HCG injection (5,000 IU IM) was given when at least one follicle measured $\geq 18 \mathrm{~mm}$ followed by timed intercourse.
\end{abstract} Results: ovulation after treatment among group I (56.7\%) compared to group II (63.3\%) ( $\mathrm{P}=0.598)$. Total number of follicles during stimulation was significantly greater in group $\mathrm{I}(6.51 \pm 0.78)$ vs. $(4.2 \pm 0.81)$ in group $\mathrm{II} ;(\mathrm{P}=0.001)$. The mean $\pm \mathrm{SD}$ of endometrial thickness at HCG injection among group I and group II was $8.4 \pm 1.76 \mathrm{~mm}$ and $8.83 \pm 1.45 \mathrm{~mm}$ respectively without significant difference between them $(\mathrm{P}=0.076)$. Pregnancy rate in group I was (13.3\%) while (26.7\%) in group II showing significant statistical difference. $(\mathrm{P}=0.017)$. Conclusion: Treatment with long letrozole protocol can produce more mature follicles and subsequently increased pregnancy rate than the short letrozole therapy.

Keywords: Extended Letrozole, Ovulation induction, clomiphene resistance, PCOS.

\section{Introduction}

Infertility has been attributed to various factors, amongst which anovulation is the cause in about $40 \%$ of all female infertility.
Polycystic Ovary Syndrome (PCOS) is one of the most common causes of anovulatory infertility, affecting 4-7\% of women (1). 
Rotterdam Criteria are used for diagnosing Polycystic Ovary Syndrome (PCOS) when a woman showed two out of the following criteria:

\section{1: Oligo- or anovulation.}

2: Clinical and / or biochemical signs of hyperandrogenism

3: Polycystic ovaries (with the exclusion of related disorders) (2).

With exclusion of other conditions with similar signs such as androgen-secreting tumors or Cushing's syndrome and thyroid dysfunction and hyperprolactinemia.

Although multiple treatments including weight reduction, clomiphene citrate, metformin, gonadotropins, and ovary cauterization have been reported to treat such condition, the efficacy still has insufficient evidence to support (3) Aromatase inhibitors (AIs) have been introduced as a new treatment option that could challenge $\mathrm{CC}$ for ovulation induction (4)

AIs can be applied for ovarian stimulation as its administration early in the follicular phase can induce ovulation by liberating the hypothalamus or pituitary from estrogen negative feedback on GnRH and gonadotropin secretion, leading to an increase in gonadotropin production which would stimulate ovarian follicular development (5).

AIs prevent the Androgen-Estrogen conversion and therefore interfere with the negative feedback at the level of the hypothalamus-pituitary. The increased pituitary gonadotropin output will in turn stimulate the ovaries (6).

In some studies, letrozole in contrast to $\mathrm{CC}$ is better as it increases endometrial thickness by upregulation of estrogen receptors, so it increases pregnancy rate and also it decreases incidence of multiple pregnancy $(7 \& 8)$.

Letrozole is reported to be effective in inducing ovulation, increased pregnancy rate, improve uterine environment, endometrial development with favorable cervical mucus, there are many regiments for letrozole use e.g. classical and extended regimen $(9 \& 10)$.

We can not ignore that there are some psychological disorders for patients with PCOS.

These disorders often consist of depression, anxiety, irregular menstrual periods, and even the infertility (11).

\section{Patients and Methods}

\section{Setting:}

This prospective clinical study included 60 infertile $\mathrm{PCO}$, and $\mathrm{CC}$ resistant women it has been carried out in the infertility clinic, endoscopy unit, Department of Gynecology and Obstetrics, Faculty of Medicine, Benha university during the period from March 2019 to September 2019. 


\section{Inclusion criteria:}

- 18-35 years old women that had been already diagnosed as primary infertility due to PCOS according to Rotterdam consensus criteria.

- Women with BMI between 18 \& 30 $\mathrm{Kg} / \mathrm{m}^{2}$.

- Uterus is normal and tubes are patent by hystero-salpingography.

- Normal serum prolactin level (5-20 $\mathrm{ng} / \mathrm{ml})$.

- Normal semen analysis of the husband.

- Patient gave history of failure to get pregnant after clomiphene therapy.

\section{Exclusion Criteria:}

- Uterine and adnexal pathology

- Ovarian cysts $>6 \mathrm{~cm}$

- Hyper- or Hypothyroidism.

- Previous surgery related to genital tract

- Impaired hepatic/renal function.

- Diabetes mellitus.

- Hyperprolactinaemia.

- Drugs likely to interfere with ovulation especially chronic use of non-Steroidal anti-inflammatory drugs, hormonal or chemotherapeutic agents.

Approval of the study was obtained from the Ethical Committee of Benha faculty of the medicine. Written consent were taken from patients.

\section{Operational design:}

A written informed consent was taken from all patients before enrolling into the study with counseling about risk and benefit of treatment after giving the participants detailed explanation about the procedure steps.

All pateinets were subjected to:

\section{1-Complete history taking including:}

- Personal history: Name, Age, marital state, address

- Menstrual history: age of Menarche, menstrual disturbance, dysmenorrhea, related symptoms.

- Obstetric history including parity and mode of delivery.

- Past history of HTN, DM.

- Family history of similar condition or diabetes.

- History of allergy to any medication.

- Surgical history of operation, laparoscopic interference, treatment of hirsutism by Laser.

- Previous induction of ovulation in previous 6 months and drugs used were endometrial thickness $<7 \mathrm{~mm}$, follicular growth and ovulation.

\section{2-Examination:}

\section{A. General examination:}

- Evaluation of the vital signs,

- Recording weight, height and calculating BMI

- Inspection of hyper androgenic manifestation e.g. hirsutism, acne

- Examination of thyroid gland. 
- Breast examination to exclude presence of galactorrhea.

\section{B. Abdominal examination:}

For hair distribution, scar of previous operation, mass, tenderness or rigidity, any abdominal or pelvic clinically detectable pathology.

\section{Bimanual pelvic examination of} both adenexa, and uterus for detection of any abnormality of female genitalia.

\section{3-Ivestigations:}

- Basal hormonal studies on Day 2 of the spontaneous menstrual cycle included serum $\mathrm{FSH}$, LH, androgen level, prolactin level and thyroid stimulating hormone.

- Basal transvaginal U/S on day3 of the cycle to examine each ovary for detecting criteria of PCOS and count number of antral follicles in both ovaries and to exclude of any basal ovarian cyst that was suspected when diameter of follicle $>1.5 \mathrm{~cm}$ ).

\section{Study design:}

It was a prospective randomization. Based on the patients' attendance order, patients with odd numbers will be considered group I (classical or short letrozole regimen) and those with even numbers will be considered group II (extended or long letrozole therapy). These patients were divided into two groups:
1-The Frist Group: included 30 patients who were treated with letrozole (Femara; Novartis pharma AG, Basle, switzerland) $2.5 \mathrm{mg}$ twice daily starting at the 2nd day of cycle for 5 days and repeated for 3 cycles (classical regimen).

2- The Second Group: included 30 who received letrozole (Femara;Novartis pharma AG, Basle, Switzerland) $2.5 \mathrm{mg}$ once daily from 2 nd day of cycle for 10 days and repeated for 3 cycles and continued for 3 cycles for all women (extended regimen) .

For all patients trans vaginal ulterasound was performed on day 9 of menstrual cycle and repeated every 2-3 days according to the follicular growth

Normal follicular size and endometrial thickness were considered 18-24 mm and 6 $\mathrm{mm}$ respectively).

\section{Follow up:}

1- Follicular monitoring was carried out for both groups with transvaginal ultrasound, started from the ninth day of cycle till attaining a mature follicle with a mean diameter of $18-22 \mathrm{~mm}$, number and size of dominant follicles, endometrial thickness and pattern were reported on day of hCG administration.

2- Then, single injection of hCG 10,000 IU was given for triggering ovulation

3- Timed intercourse was advised from the day of hCG and for 4 days. 
4- Clinical pregnancy detected by serum pregnancy test and transvaginal U/S which detected IUGS and fetal pulsation. The doctor who did ultrasound examination was blinded to the treatment protocol \& patients' group.

5- Follow up of both groups was done for 3 cycles.

\section{Outcome measures:}

\section{1-Primary outcome measures:}

Included the number of mature follicles and endometrial thickness in each group.

\section{3-Scondary outcome measures:}

Included pregnancy rate, and multiple pregnancies in each group.

\section{Results:}

There was no statistically significant difference in any demographic characters among women of studied groups, Table 1

Table 2, shows that there is no significant difference between the studied groups as regard their clinical presentation. .

Table 3, showing that total number of follicles during stimulation was significantly greater in the long letrozole group $(6.51 \pm 0.78)$ vs. $(4.2 \pm 0.81)$ in short letrozole group; $\mathrm{P}=0.001$ ).

Table 4, showed that the number of patients with follicles measuring $<14 \mathrm{~mm}$ was greater $(40 \%)$ in the short letrozole group compared to the long letrozole group
Data management and Statistical Analysis

Data entry, processing and statistical analysis was carried out using MedCalc ver. 18.2.1 (MedCalc, Ostend, Belgium). Tests of significance (Kruskal-Wallis, Wilcoxon's, Chi square, logistic regression analysis, and Spearman's correlation) were used. Data were presented and suitable analysis was done according to the type of data (parametric and non-parametric) obtained for each variable. P-values less than $0.05(5 \%)$ was considered to be statistically significant.

$(30 \%)$, the number of patients with follicles measuring 14-17 mm was greater $(13.3 \%)$ in long letrozole group compared to short letrozole group (10\%), while the number of patients with follicles measuring $\geq 18 \mathrm{~mm}$ was greater $(56.7 \%)$ in the long letrozole group compared to the short letrozole group (50\%) without statistical significance $(\mathrm{P}=0 . .981)$.

Table 5, showed that the mean of endometrial thickness at HCG injection among group I (short letrozole group) and group II (long letrozole group) \pm SD was $8.4-1.76 \mathrm{~mm}$ versus $8.83 \pm 1.45$ respectively without significant difference between the two groups $(\mathrm{P}=0.076)$.

Table 6, is showing that percentage of patients ovulated after treatment among 
group I (short letrozole group) and group II

(long letrozole group) was $56.7 \%$ vs $63.3 \%$ respectively with significant difference between the two groups $(\mathrm{P}=0.598)$.

Table 7, showing that pregnancy occurred in 4 out of 30 patients in the short letrozole group (13.3\%) and in 8 out of 30 patients

Table (1): Demographic data of study population
$(26.7 \%)$ in the long letrozole group. One twin pregnancy occurred in the long letrozole group (26. $7 \%$ of pregnant cases). Comparison between the groups according to post treatment pregnancies was statistically significant as $\mathrm{P}$ - value $=0.017$.

\begin{tabular}{|c|c|c|c|c|c|c|c|c|}
\hline & \multicolumn{2}{|c|}{$\begin{array}{l}\text { Short } \\
\text { group }(\mathbf{N}=\mathbf{3 0})\end{array}$} & letrozole & \multicolumn{3}{|c|}{ Long letrozole group $(\mathrm{N}=30)$} & \multirow[t]{2}{*}{ t-test } & \multirow[t]{2}{*}{$P$ value } \\
\hline & Range & Mean & SD & Range & Mean & SD & & \\
\hline $\begin{array}{l}\text { Age } \\
\text { (years) }\end{array}$ & $18-35$ & 25.10 & 4.25 & $18-34$ & 24.62 & 3.33 & 0.461 & $\begin{array}{c}0.532 \\
\text { (NS) }\end{array}$ \\
\hline $\begin{array}{l}\text { Weight } \\
\text { (kg) }\end{array}$ & 46.5- 95 & 68.52 & 19.11 & 49- 96 & 68.44 & 18.81 & 0.014 & $\begin{array}{l}0.988 \\
(\mathrm{NS})\end{array}$ \\
\hline $\begin{array}{l}\text { Height } \\
\text { (meter) }\end{array}$ & $1.47-1.79$ & 1.65 & 0.103 & $1.52: 1.75$ & 1.64 & 0.106 & 0.338 & $\begin{array}{r}0.077 \\
(\mathrm{NS})\end{array}$ \\
\hline $\begin{array}{l}\text { BMI } \\
(\mathrm{kg} / \mathrm{m} 2)\end{array}$ & $\begin{array}{l}19.06- \\
34.07\end{array}$ & 25.04 & 4.33 & $\begin{array}{l}\text { 19.68: } \\
35.04\end{array}$ & 27.01 & 4.59 & 1.56 & $\begin{array}{l}0.125 \\
(\mathrm{NS})\end{array}$ \\
\hline
\end{tabular}

Table (2): Clinical presentation among studied patients

\begin{tabular}{ccccc}
\hline & & $\begin{array}{c}\text { Short letrozole group } \\
(\mathbf{N = 3 0 )}\end{array}$ & $\begin{array}{c}\text { Long letrozole group } \\
(\mathbf{N = 3 0 )}\end{array}$ & $\begin{array}{l}\boldsymbol{2} \\
\text { P value }\end{array}$ \\
\hline$\bullet$ & Oligo/anovulation & $8(26.7 \%)$ & $10(33.3 \%)$ & \\
- & Hyperandrogenism & $4(13.3 \%)$ & $3(10 \%)$ & .587 \\
\hline
\end{tabular}

Table (3): Mean number of follicles in both groups

\begin{tabular}{|c|c|c|c|c|}
\hline & & $\begin{array}{l}\text { Short letrozole group } \\
(\mathrm{N}=18)\end{array}$ & $\begin{array}{l}\text { Long letrozole group }(\mathrm{N}= \\
21)\end{array}$ & P-value \\
\hline Total number of & Range & $3-5$ & $5-8$ & \\
\hline follicles & Mean \pm S. D & $4.2 \pm 0.81$ & $6.51 \pm 0.78$ & $<0.001$ \\
\hline
\end{tabular}

Table (4): Number of patients with different follicle size in group I (short letrozole group) and group II (long letrozole group):

\begin{tabular}{|c|c|c|c|c|}
\hline \multicolumn{2}{|l|}{ Biggest follicle size } & $\begin{array}{r}\text { Short letrozole group } \\
(\mathrm{N}=30)\end{array}$ & $\begin{array}{c}\text { Long letrozole group } \\
(\mathbf{N}=\mathbf{3 0})\end{array}$ & P-value \\
\hline $\begin{array}{lll}\text { Patients } & \text { with } \text { biggest }\end{array}$ & $\mathrm{N}$ & 12 & 9 & \\
\hline follicles $<14$ & & $40 \%$ & $30 \%$ & \\
\hline Patients with & $\mathrm{N}$ & 3 & 4 & 0.981 \\
\hline follicles 14-17 & $\%$ & $10 \%$ & $13.3 \%$ & \\
\hline Patients with biggest & $\mathrm{N}$ & 15 & 17 & \\
\hline follicles $\geq 18 \mathrm{~mm}$ & $\%$ & $50 \%$ & $56.7 \%$ & \\
\hline Total & $\mathrm{N}$ & 30 & 30 & \\
\hline
\end{tabular}


Table (5): Mean of Endometrial thickness at HCG (mm) in group I (short letrozole group) and group II (long letrozole group):

\begin{tabular}{|c|c|c|c|c|}
\hline & & $\begin{array}{l}\text { Short letrozole } \\
\text { group }(\mathrm{N}=30)\end{array}$ & $\begin{array}{l}\text { Long letrozole } \\
\text { group }(\mathrm{N}=30)\end{array}$ & $\begin{array}{l}\text { P- } \\
\text { Value }\end{array}$ \\
\hline & Range & $4-10$ & $5-11$ & \\
\hline $\begin{array}{l}\text { Endometrial } \\
\text { thickness at } \\
\text { HCG(mm) injection }\end{array}$ & Mean \pm S.D & $8.4-1.76$ & $8.83 \pm 1.45$ & 0.076 \\
\hline
\end{tabular}

Table (6): Percentage of ovulation occurred after treatment in group I (short letrozole group) and group II (long letrozole group):

\begin{tabular}{lllll}
\hline & & $\begin{array}{l}\text { Short letrozole group } \\
(\mathbf{N = 3 0 )}\end{array}$ & $\begin{array}{l}\text { Long letrozole group } \\
(\mathbf{N = 3 0 )}\end{array}$ & P-value \\
\hline \multirow{2}{*}{ No } & $\mathrm{N}$ & 14 & 12 & \\
& $\%$ & $46.7 \%$ & $40 \%$ & $\mathbf{0 . 6 8 3}$ \\
Yes & $\mathrm{N}$ & 16 & $60 \%$ & \\
& $\%$ & $53.3 \%$ & 30 & \\
& $\mathrm{~N}$ & 30 & $\mathbf{1 0 0 \%}$ & \\
\hline
\end{tabular}

Table (7): Number of pregnancies after therapy in group I (short letrozole group) and group II (long letrozole group):

\begin{tabular}{|c|c|c|c|c|}
\hline Pregnancies & & $\begin{array}{l}\text { Short letrozole group } \\
(\mathrm{N}=30)\end{array}$ & $\begin{array}{l}\text { Long letrozole group } \\
(\mathrm{N}=30)\end{array}$ & P-value \\
\hline \multirow[t]{2}{*}{ No } & $\mathrm{N}$ & 26 & 22 & \multirow{6}{*}{$0.017 *$} \\
\hline & $\%$ & $86.7 \%$ & $73.3 \%$ & \\
\hline \multirow{4}{*}{ Total } & $\mathrm{N}$ & 4 & 8 & \\
\hline & $\%$ & $13.3 \%$ & $26.7 \%$ & \\
\hline & $\mathrm{N}$ & 30 & 30 & \\
\hline & $\%$ & $100.0 \%$ & $100 \%$ & \\
\hline
\end{tabular}

\section{Discussion}

In our study we compared the extended letrozole regimen \& classical one in treatment of clomiphene resistant $\mathrm{PCO}$ patients aiming at the identification of the appropriate protocol for its use in ovulation induction.

The total number of follicles during stimulation was significantly greater in the long letrozole group $(6.51 \pm 0.78)$ vs. (4.2 \pm 0.81 ) in short letrozole group; $\mathrm{P}=0.001$ ). 968
This coped with study conducted before where it was found that the mean value \pm SD for total number of follicles after stimulation was significantly greater in the long letrozole group $(6.48 \pm 0.68)$ vs. $(4 \pm 0.91)$ in short letrozole group; $\mathrm{P}=0.001)$. (12)

These results are in agreement with the results of study done by other researchers (13) who found that the total numbers of 
follicles during stimulation was significantly greater in the long letrozole group $(6.7+/-0.3$ vs. $3.9+/-0.4)$.

Another study (14) proved that there was no significant difference in the number of intermediate $(0.83 \pm 0.75$ vs $0.62 \pm 0.76)$ and mature follicles $(1.13 \pm 1.11$ vs $1.22 \pm$ 1.03) between the two groups.

In the current study the mean of biggest follicles size $(\mathrm{mm})$ was greater $(19.83 \pm 4.12)$ in the long letrozole group compared to short letrozole group (20.1 \pm 3.46 ), without statistical differences $(\mathrm{P}=0.951)$.

This coped with study conducted before (12) where it was found that the mean of biggest follicles size $(\mathrm{mm})$ was greater $(19.095 \pm 2.26)$ in the long letrozole group when compared to short letrozole group (18.83 \pm 2.12), without statistical differences $(\mathrm{P}=0.712)$.

In the present study, the number of patients with follicles measuring $\geq 18 \mathrm{~mm}(56.7 \%)$ and between $14-17 \mathrm{~mm} \quad(13.3 \%)$ was greater in the long letrozole group $(\mathrm{P}=0.774)$. These results came comparable with the results of other researchers.(13) In the present study, The mean of endometrial thickness at HCG injection among group I and group II \pm SD was $8.4-1.76 \mathrm{~mm}$ versus $8.83 \pm 1.45$ respectively without significant difference between the two groups $(\mathrm{P}=0.076)$.
This was in agreement with study conducted by a group of researchers (12) who reported that the mean of endometrial thickness at the time of HCG administration $\pm \mathrm{SD}$ in group I was $8.2 \pm$ $1.56 \mathrm{~mm}$ versus $8.933 \pm 1.64$ among group II. There was no significant difference in the endometrial thickness at the time of HCG administration between the two groups $(\mathrm{P}=0.081)$. That came hand in hand with the results of other studies (13) and (14).

In the present study, percentage of patients ovulated after treatment among group I and group II was $56.7 \%$ vs $63.3 \%$ respectively with significant difference between the two groups $(\mathrm{P}=0.598)$.

This was in agreement with study conducted previously (12) where it was reported that percentage of ovulation occurred after treatment among group II was greater than Group I $(63.3 \%$ vs $56.7 \%$, respectively). Also came in agreement with the study Badawy_et al. (13) who reported that (The number of ovulating patients was greater in the long letrozole group $(65.7 \%$ vs. $61.8 \%)$, but without statistical differences).

On the other hand came in contrast with this present study, it was proved that (Ovulation occurred in 90 and $89.2 \%$ of patients in group 1 and 2). (14)

The present study showed that pregnancy occurred in 4 out of 30 patients in the short 
letrozole group (13.3\%) and in 8 out of 30 patients $(26.7 \%)$ in the long letrozole group. One twin pregnancy occurred in the long letrozole group (26. $7 \%$ of pregnant cases). Comparison between the groups according to post treatment pregnancies was statistically significant as $\mathrm{P}$ - value $=$ 0.017 .

This was in agreement with study conducted before which reported that pregnancy occurred in 4 out of 30 patients in the short letrozole group (13.3\%) and in 6 out of 30 patients $(20 \%)$ in the long letrozole group. One twin pregnancy occurred in the long letrozole group (16.67\% of pregnant cases). Comparison between the 2 groups according to post treatment pregnancies was in favor of long group and P-value was> 0.05. (12)

These results came comparable with a group of researchers, as their study showed that pregnancy occurred in 28 of 225 cycles in the short group (12.4\%) and 38 of 219 cycles $(17.4 \%)$ in the long letrozole group, and the difference was statistically significant (13). In contrast to these result, it was shown that there were no significant differences between both groups with regard to clinical pregnancy rate $(22.06 \%$ vs. $16.18 \%$, respectively) (15), and in disagreement also with the study which showed that the pregnancy rate was $25.8 \%$ in group 1 and $21.2 \%$ in group 2 without significant difference (14).
Depending on results of the present study, we concluded that the long letrozole therapy (5 $\mathrm{mg}$ for 10 days) can produce more and bigger mature follicles and better endometrial thickness and subsequently more pregnancies than the short letrozole therapy (5 days) and so, the long letrozole therapy (5 $\mathrm{mg}$ for 10 days) should take the superiority of ovulation induction in PCOS patients.

This conclusion came in agreement with other sudies (13) and (15) which proved (extended letrozole regimen/HPuFSHGnRHant protocol was more costeffective than short letrozole regimen/HPuFSH- GnRHant protocol in poor responders undergoing IVF-ET).

In 2012 a study was done to reach a conclusion that long letrozole regiment is less cost than Laparoscopic Ovarian Drilling with the same outcomes (16) .

In conclusion the long letrozole therapy (5 $\mathrm{mg}$ for 10 days) can produce more and bigger mature follicles and better endometrial thickness and subsequently more pregnancies than the short letrozole therapy (5 days).

\section{Conclusion}

The long letrozole protocol can produce more mature follicles and subsequently more pregnancies than the short letrozole therapy. 


\section{References:}

1- Ehrmann DA, (2005): Polycystic ovary syndrome. N Engl J Med 2005;352(12):1223-1236

2- Kamboj MK, Bonny AE,(2017): Polycystic ovary syndrome in adolescence: diagnostic and therapeutic strategies. Transl Pediatr., 6:248-55.

3- Marciniak A, Lejman-Larysz K, NawrockaRutkowska,(2018): Polycystic ovary syndrome current state of knowledge. Pol Merkur Lekarski, 44:296-301.

4- Mitwally F and Casper F ,(2006): Potential of aromatase inhibitors for ovulation and superovulation induction in infertile women. Drugs ; 66(17): 2149-2160.

5- Lidor, A. L., Goldenberg, M., Cohen, S. B., Seidman, D. S., Mashiach, S., \& Rabinovici, J. (2000). Management of women with polycystic ovary syndrome who experienced premature luteinization during clomiphene citrate treatment. Fertility and sterility, 74(4), 749-752.

6- Mitwally M, Biljan M, Casper R, (2005): Pregnancy outcome after the use an aromatase inhibitor for ovarian stimulation. Am J Obstet and Gynec., 192(2): 381-386.

7- Futterweit W,(2007). Polycystic Ovary Syndrome: A Common Reproductive and Metabolic Disorder Necessitating Early Recognition and Treatment. Prim Care Clin Office Pract 34 761-789.

8- Cipkala-Gaffin J, Talbott EO,Song MK,(2012): Associations between psychologic symptoms and life satisfaction in women with polycystic ovary syndrome. J Womens Health (Larchmt), 21:179-87.

9- Holzer H,CasperR and Tuland T (2006), new era in induction of ovulation,Fertility and sterility vol 85no2pp277-287
10- -Miller, W. R., Bartlett, J., Brodie, A. M., Brueggemeier, R. W., Di Salle, E., Lønning, P. E., ... \& Goss, P. E. (2008). Aromatase inhibitors: are there differences between steroidal and nonsteroidal aromatase inhibitors and do they matter?. The oncologist, 13(8), 829-837.

11- Cooney LG, Dokras A, (2017): Depression and anxiety in polycystic ovary syndrome: etiology and treatment. Curr Psychiatry Rep., 19:83.

12- El-Aziz, M., Fouad, M. S., \& Ouf, T. F. (2019). Short Letrozole Therapy Vs Extended (Long) Letrozole Therapy for Induction of Ovulation in Women with Polycystic Ovary Syndrome. Egyptian Journal of Hospital Medicine, 74(8)

13- Badawy A, Mosbah A, Tharwat A et al. (2009): Extended letrozole therapy for ovulation induction in clomiphene-resistant women with polycystic ovary syndrome: a novel protocol., 92(1):236-9.

14- Ramezanzadeh, F., Nasiri, R., Yazdi, M. S., \& Baghrei, M. (2011). A randomized trial of ovulation induction with two different doses of Letrozole in women with PCOS. Archives of gynecology and obstetrics, 284(4), 1029.

15- Fouda UM, Sayed AM, (2011): Extended high dose letrozole regimen versus short low dose letrozole regimen as an adjuvant to gonadotropin releasing hormone antagonist protocol in poor responders undergoing IVF-ET. https://www. ncbi. nlm.nih.gov/pubmed/21714697

16- Morad A. and Abdel Salam M,(2012): Extended letrozole regimen versus laparoscopic ovarian drilling for ovulation induction in clomiphene citrate resistant cases in polycystic ovary syndrome. J. Egypt .Soc. Gynaecol. Obstet. Vol.38, No.2, 67968

To cite this article: Ahmed W. Anwar, Ehab E. Barakat, Ahmed M. Bayomey, Manal H. Ahmed. Extended Letrozole Regimen for Treatment of Clomiphene Resistant Polycystic Ovary Syndrome Patients. BMFJ 2021;38(3): 962-971. DOI: 10.21608/bmfj.2021.18571.1126 
Original article 